\title{
Study of structural changes of water confined in Brij-30 reverse micelles: Revealing influence of ionic additives
}

\author{
Manoni Kurtanidze ${ }^{\mathrm{a}}$, Tinatin Butkhuzi ${ }^{\mathrm{a}, \mathrm{b}, \mathrm{c}}$, Marina Rukhadze ${ }^{\mathrm{a}, \mathrm{d}}$, Nino Kokiashvili ${ }^{\mathrm{a}}$, , George \\ Bezarashvili ${ }^{\mathrm{a}}$, Julien Marcus ${ }^{\mathrm{d}}$, Werner Kunz ${ }^{\mathrm{d}}$ and Ketevan Sigua ${ }^{\mathrm{a}, \mathrm{e}}$
}

${ }^{a}$ Faculty of Exact and Natural Sciences, Ivane Javakhishvili Tbilisi State University, 3

I.Chavchavadze ave, Tbilisi, 0128, Georgia

${ }^{\mathrm{b}}$ Department of Physics , New York City College of Technology, 300 Jay Street, Brooklyn, New York 11201, USA

${ }^{c}$ Department of Chemistry, The City College and The city University of New York, 160 Convent Avenue, New York, NY 10031-9198,USA

${ }^{\mathrm{d}}$ University of Regensburg, Institute of Physical and Theoretical Chemistry, Universitatstraße 31, Regensburg, D-93053, Germany

${ }^{\mathrm{e}}$ Andronikashvili Institute of Physics, I. Javakhishvili Tbilisi State University, 6 Tamarashvili

Str., Tbilisi 0177, Georgia

* Corresponding author. Tel.: +995 599197525.

E-mail address: marina_rukhadze@yahoo.com (M. Rukhadze).

\begin{abstract}
The microenvironment of water droplets of nonionic polyoxyethylene (4) lauryl ether reverse micelles was investigated using infrared, ultraviolet-visible and nuclear magnetic resonance spectroscopy, also by dynamic light scattering. The different influence of kosmotropic and chaotropic ionic additives on the microstructure of reverse micelles was revealed. The values of chemical shift in the presence of structure-breaking perchlorate ions are higher than their values in case of structure-making acetate ions according to measurements by proton magnetic resonance spectroscopy. Deconvolution of the $\mathrm{O}-\mathrm{H}$ stretching vibrational absorption spectra in the region of $3000-3800 \mathrm{~cm}^{-1}$ into three subpeaks with a Monte Carlo method showed that perchlorate ions promote an increasing of free water fraction in the water pools of the reverse micelles, whereas acetate ions support formation of bound water. Influence of salt additives results in slight different sizes of water droplets, measured by dynamic light scattering method. Different influence of kosmotropic and chaotropic anions on binding constant $\mathrm{K}_{\mathrm{b}}$ of optical probe to ethylene oxide groups was revealed.
\end{abstract}


Keywords: Brij-30 reverse micelle; Ionic additives; Chemical shift; Free and bound water; Sizes of Water droplets; Binding constant.

\section{Introduction}

The water core of reverse micelles represents a polar microenvironment confined in nonpolar organic phase. Reverse micelles attracted attention in different areas of life sciences [1,2]. Reverse micelles are used as artificial model of biomembranes due to resemblance of their structure [3]. The anionic surfactant sodium 1,4-bis-2-ethylhexylsulfosuccinate (AOT) is unchangeable for biomimicing investigations, however nonionic surfactants provide milder environment for encapsulation of enzymes and proteins inside the water nanocages of reverse micelles. For example, catalase incorporated into reverse micelles of the nonionic polyoxyethylene (4) lauryl ether (Brij-30) reverse micelles exhibits superactivity [4]. Doping the interface of anionic reverse micelles with nonionic surfactants is frequently used for solubilization of biological macromolecules in reverse micelles, because of weak interaction of nonionic surfactants with proteins in comparison with anionic surfactants [5]. Moreover, the non-ionic surfactant Brij-30 is a non-toxic, biocompatible surfactant. Therefore the preparation of Brij-30-based microemulsions can be of considerable pharmaceutical interest in the field of drug delivery [6, 7].

Reverse micelles have been investigated with different physicochemical methods depending complex structure of water droplets. These methods include infrared (IR), ultraviolet-visible (UVviz), fluorescence and nuclear magnetic resonance (NMR) spectroscopic techniques, also conductivity, calorimetry, dynamic light scattering, small angle X-ray scattering methods, etc [816].

Our recent investigations are devoted to the investigations of structure of sodium bis (2ethylhexyl) sulfosuccinate reverse micelles by UV-visible, IR and NMR spectroscopic methods [17]. In the presented paper the properties of Brij-30 reverse micelle microstructure were investigated using infrared, UV-visible, nuclear magnetic resonance spectroscopic and dynamic light scattering methods in the presence of structure-making and structure-breaking ionic additives.

\section{Materials and methods}

\subsection{Preparation of the reverse microemulsions.}

Microemulsions were prepared on the basis of Brij-30 (Fluka, BioChemika, Switzerland). 
The Brij-30 has a molecular formula of $\mathrm{C}_{12} \mathrm{H}_{25}\left(\mathrm{OCH}_{2} \mathrm{CH}_{2}\right)_{4} \mathrm{OH}$ (Figure 1). The hydrophiliclipophilic balance (HLB) of Bri-30 is equal to 9.7 and the critical micelle concentration (CMC) is in the range of 7 to $14.52 \mathrm{mgL}^{-1}$ [18]. The other constituents of microemulsion were hexane, water, water solutions of sodium acetate and potassium perchlorate $(0.05$ and $0.1 \mathrm{M})$. The water content $\mathrm{W}_{0}$ was calculated as water-surfactant molar ratio $\mathrm{W}_{0}=\left[\mathrm{H}_{2} 0\right] /[\mathrm{Surf}]$. Transparent onephase solutions were achieved through gentle shaking of the mix of certain amounts of hexane, Brij-30 and water (or solutions of salts). For systems of low water content, the solutions became monophasic quickly. All spectroscopy experiments were performed on stable, one-phase systems at room temperature.

\subsection{Apparatus and conditions.}

IR absorption spectra were recorded in a one beam Varian 660-FTIR spectrophotometer equipped with a $0.093 \mathrm{~cm}$ path length sodium chloride window. All the IR spectra of different $\mathrm{H}_{2} \mathrm{O} / \mathrm{Brij}-30$ molar ratio $\left(\mathrm{W}_{0}\right)$ were obtained between 4000 and $400 \mathrm{~cm}^{-1}$ at room temperature. To study the microstructure of the solubilized water, the $\mathrm{O}-\mathrm{H}$ stretching vibrational absorption spectra in the region of $3000-3800 \mathrm{~cm}^{-1}$ were fitted into three subpeaks. The curve fitting was performed by using Origin 6.5. Gauss function was chosen to fit the overlapped peaks. Gaussian curve fitting was achieved with a Monte Carlo method. The process is described by the following mathematical model:

$$
y t(x)=\sum_{k=1}^{3} a_{k} e^{\left(0.5\left(\left(x-x_{k}\right) / \omega_{k}\right)^{2}\right)}
$$

where $\boldsymbol{a}_{\boldsymbol{k}}, \boldsymbol{x}_{\boldsymbol{k}}, \boldsymbol{\omega}_{\boldsymbol{k}}$ are unknown parameters. Experimental data are processed by method Monte-Carlo. The values of unknown parameters are played by random numbers within permissible limits. Among them only one set is chosen, which gives the minimum value of the mean-square deviation:

$$
S D=\sqrt{\frac{x^{2}}{(n-m)}},
$$

where $\chi^{2}=\sum_{i=1}^{n}\left(y e_{i}-y t\left(x_{i}\right)\right)^{2}, y e_{i}$ represent the values of experimental points, $n$ corresponds to the number of experimental points, $\boldsymbol{m}$ is the number of parameters. SD is standard deviation of deconvoluted values from the experimental data. 
NMR spectra were recorded in n-hexane on an Agilent Mercury 300 NMR spectrometer operating at $300 \mathrm{MHz}$. Tetramethylsilane was added as an internal reference standard for chemical shift measurements. Before measurement, the spectrometer was locked at $\mathrm{D}_{2} \mathrm{O}$ frequency for filed/frequency stabilization and shimmed using gradient shimming protocol.

Dynamic Light Scattering (DLS) measurements. Water droplet-size measurements were performed with a commercial goniometer (CGS-2, ALV-GmbH, D-Langen) equipped with a vertical-polarized 22-mW HeNe laser (wavelength $\lambda=632.8 \mathrm{~nm}$ ), a fiber optical detection unit with an avalanche photodiode, and an ALV-5000/E multiple $\tau$ correlator. Cylindrical light-scattering cells of $10 \mathrm{~mm}$ outer diameter were used. All measurements were performed at $90.028^{\circ}$ detection angle and at $25^{\circ}$. The solutions prepared for light scattering were filtered using a syringe filter with $200 \mathrm{~nm}$ pore size. All solns. were left to equilibrate at least $2 \mathrm{~h}$ before measurements. An automatic process was performed with a 10-runs method for each sample. The particle sizer and its attendant software (ALV-5000/E-Win V1.4.8.by ALV-GmbH, D-Langen) provided first the timecorrelation function of the scattered intensity. The decrease of this correlation function with displacement time (called 'lag time') can be used to extract information about the diffusion coefficient of a particle or droplet in solution. The measured diffusion coefficient can be used to calculate a hydrodynamic radius $\left(R_{h}\right)$ of the droplet using the Stokes-Einstein equation:

$R_{h}=k T / 6 \pi \eta D$

where $k$ is the Boltzmann constant, $T$ the abs. temp., $\eta$ the viscosity of the continuous phase, and $D$ is the diffusion coefficient. The data are first analyzed by cumulant analysis to obtain an average diffusion coefficient and subsequently by CONTIN analysis in order to obtain information about the entire distribution of the particle size (monomodal or multimodal) [19,20].

UV-vis absorption spectra were recorded in a UV-visible spectrophotometer Optizen POP using $1 \mathrm{~cm}$ path length cells. As optical probe o-nitroaniline (o-NA) was used. Absorbance of the samples was measured after 1 hour from preparation of reverse microemulsions. Binding constants of o-NA with Brij-30 micelles were calculated by absorption data of o-NA at two wavelengths 376 and $400 \mathrm{~nm}$ in hexane (0.0 M Brij-30) and 0.2 M Brij-30. Concentrations of free and bound o-NA were determined by equation systems at intermediate concentrations of Brij-30. 
Changes in absorption maximum are determined by binding of o-NA with Brij30 polar head groups:

$$
(\mathrm{o}-\mathrm{NA})_{\mathrm{f}}+\mathrm{Brij}-30 \leftrightarrows(\mathrm{o}-\mathrm{NA})_{\mathrm{b}}
$$

where $(\mathrm{o}-\mathrm{NA})_{\mathrm{f}}$ and $(\mathrm{o}-\mathrm{NA})_{\mathrm{b}}$ correspond to free and bound forms of this optical probe. Concentrations of free and bound o-NA were determined by equation systems at intermediate concentrations of Brij30:

$$
\left\{\begin{array}{l}
\varepsilon_{f}^{376} \times[o-N A]_{f}+\varepsilon_{b}^{376} \times[o-N A]_{b}=A_{376} \\
\varepsilon_{f}^{400} \times[o-N A]_{f}+\varepsilon_{b}^{400} \times[o-N A]_{b}=A_{400}
\end{array}\right.
$$

where $\mathrm{A}_{376}$ and $\mathrm{A}_{400}$ represent optical densities of microemulsion systems measured spectrometrically and correspond to wave lengths 376 and $400 \mathrm{~nm}$ respectively. $\varepsilon_{f}$ and $\varepsilon_{b}$ are reduced extinction coefficients for free and bound forms of o-NA. They were determined for wave lengths 376 and $400 \mathrm{~nm}$ on the basis of preliminary experiments.

The strength of binding of o-NA with Brij-30 micelles was estimated using the binding constant $(\mathrm{Kb})$. Binding constants are calculated on the basis of stoichiometric ratio 1:1 between o-NA and Brij-30. Binding constants of o-nitroaniline with Brij-30 micelles were calculated by absorption data of o-nitroaniline at two wavelengths 376 and $400 \mathrm{~nm}$ in hexane (0.0 M Brij-30) and 0.2M Brij-30 by following equation:

$$
K_{b}=\frac{[o-N A]_{b}}{[o-N A]_{f}[B r i j-30]_{0}}
$$

\section{Results and Discussion}

\subsection{Nuclear magnetic resonance spectroscopic study.}

${ }^{1} \mathrm{H}$ NMR study. The ${ }^{1} \mathrm{H}$ NMR spectra of Brij-30 in hexane is given in Fig.1a. Resonances related with the hydrophobic alkyl group (D) of Brij-30 are between 0.6-1.6 ppm, but the oxyethylene (A, B and C) protons appear between 3.3 and $3.8 \mathrm{ppm}$. The profile of the spectrum in the oxyethylene diapason $(3.3-3.8 \mathrm{ppm})$ is changed after addition of water because oxyethylene groups are wetted with water (Fig.1b). The signals due to $\mathrm{OH}$ groups appeared as a 
single peak, which reflects a rapid exchange between the protons of water and terminal $\mathrm{OH}$ protons of Brij-30, which is present in both free and micellar forms. The $\mathrm{OH}$ proton chemical shift is changed downfield from 4.02 to $4.67 \mathrm{ppm}$ as the water content is increased from $\mathrm{W}=1$ till $\mathrm{W}=8$ respectively (Fig.2).

The difference between the values of the $\mathrm{OH}$ proton chemical shifts is observed in the presence of acetate and perchlorate ions in the water core of reverse micelles (Fig.3, W=1). Generally NMR experimental spectrum of reverse microemulsion represents a weighted average of the spectrum corresponding to free and aggregated surfactant, which are in rapid exchange. It is impossible to obtain NMR spectrum only for micellar surfactants, because of the existence of free surfactant in reverse miceroemulsion. The chemical shift of both free and micellar surfactant is strongly dependent on micelle size [12]. Hence, the higher value of the $\mathrm{OH}$ proton chemical shift in the presence of perchlorate, than it is in case of acetate ions, is supposed to be related to the different influence of the mentioned ions on the sizes of micelles.

It is well known that sizes of the reverse micelles are changed significantly with the changes of concentration of surfactant [21]. Generally, the following regularities are observed in reversed microemulsions: a) The volume of the reverse micelle is changed with the change of water content at the constant concentration of surfactant; b) Increasing of concentration of surfactant should cause decreasing of the volume of reverse micelle at constant content of water; c) The volume of reverse micelle should be held constant if the ratio of surfactant concentration and water content remains constant, only the number of micelles will be changed.

We tried to decrease surfactant concentration when the amount of water additive was held constant. With other words we tried to increase $\mathrm{W}_{0}$ by decreasing the surfactant concentration at constant water content. This action should cause changes in micellar sizes, viz. the sizes of micelles should be increased not because of increasing water concentration, but due to the decreasing of surfactant concentration. In such conditions chemical shift is supposed to go to higher frequencies, which is confirmed experimentally (Fig.3, W=1.5 and 2.0). In addition, the value of $\delta$ in the presence of perchlorate ions is higher than its value in the presence of acetate ions, that indicates the possible contribution of perchlorate and acetate ions in the sizes of micelles. 


\subsection{Dynamic light scattering study}

The $R_{h}$ decreases gradually with increasing of Brij-30 concentration in spite of the core of microemulsion is modified by water or water solutions of sodium acetate or potassium perchlorate. The changes of the micelle sizes are considerable, e.g. the sizes of microemulsion droplets containing 0.1, 0.5 and 1.0 M Brij-30 are 4.20, 2.99 and 2.54 $\mathrm{nm}$ respectively in case of the same value of water/surfactant ratio $(\mathrm{W}=1)$. By contrast, the sizes of micelles are not changed if salts are introduced at otherwise the same conditions. In our opinion, it is hard to reveal the specific effect of ions on the sizes of micelles in presence of the considerable concentration of Brij-30. In other words, we suggest that any specific ion effect is superimposed by the effect of Brij-30. Because of this we tried to reveal specific ion effects through varying of $\mathrm{W}_{0}$ by increasing the water content at constant Brij-30 concentration. The data shown in Table 1 displays that the difference between sizes of micelles are more pronounced in case of $0.1 \mathrm{M}$ salt content, viz. the sizes of micelles increases more in the presence of perchlorate ions than in the presence of acetate ions. The sizes of water droplets were measured also in case of sodium fluoride and potassium iodide, as an additional couple of kosmotropic and chaotropic anions. The results are similar, viz. when $\mathrm{W}_{0}=8$, in the presence of chaotropic iodide and perchlorate ions, the sizes of water droplets are 7.47 and $7.36 \mathrm{~nm}$, but in case of fluoride and acetate ions the sizes are 6.09 and $6.61 \mathrm{~nm}$ respectively, which indicates that the sizes of water droplets are smaller in the presence of kosmotropic anions in comparison with chaotropic ions.

\subsection{Infrared spectroscopic study.}

In order to estimate an influence of additives of salt solutions on the ratio of different states of water in the water droplets of reverse microemulsions (viz. on the ratio of free, bound and trapped water), the known method of decomposition of the $\mathrm{O}-\mathrm{H}$ stretching vibrational absorption spectra in region 3000-3800 cm-1 into three subpeaks was used. This method was proposed by Jain at all for studying the structure of water encapsulated in sodium bis (2ethylhexyl) sulfosuccinate reverse micelles [9]. Later analogous method was used for decomposition of the $\mathrm{OH}$ band into three Gaussians for water confined into nonionic reverse micelles, where each of the Gaussians was ascribed to a "particular type" of water molecules: "network water" molecules, "intermediate water" molecules and "multimer water" molecules [22,23]. "Network", "intermediate" and "multimer" water correspond to the free, bound and trapped water [9]. "Network water" or free water corresponds to the lower energy gaussian, is 
expected to arise from water molecules involved in transient networks that break and form continuously [22,23]. The free water molecules, however, have strong intermolecular hydrogen bonding, leading to an array of water molecules that further shifts the band frequency to the lower side of the spectrum [9]. "Intermediate water" (intermediate energy gaussian) is ascribed to water molecules that are somewhat connected to other water molecules, though less than those participating to the previously mentioned percolating networks [22,23].. In the bound water layer, the water molecules are hydrogen bonded with the polar head groups of surfactant, which results in absorption in the low-frequency region of the IR spectrum [9]. "Multimer water" (higher energy gaussian) corresponds to water molecules arranged either within dimers, trimmers or higher order multimers [22,23]. The trapped water molecules are matrix isolated and monomeric in nature and they absorb in the high-frequency region [9].

The fractions of bound, trapped and free water were calculated on the basis of their peak areas regarding to total peak area of the $\mathrm{OH}$ stretching band of water and are presented in Table 2. According to the IR study, the ratio of free, bound and trapped water in case of pure water is close to the same ratio in the presence of acetate ions in the water core of Brij30 reverse micelles. Besides the fraction of free water increases approximately 2 times in the presence of perchlorate ions, in comparison with additives of acetate ions. At the same time the fraction of bound water is 2 times less in case of perchlorate ions than in the presence of acetate ions (Figs 4-6).

In order to explain this we based on the following publications [24,25]. The large chaotropic anions penetrate more deeply into the interfacial region of the lipid bilayer interior since the larger ions are more hydrophobic and energetically stable in a hydrophobic environment, therefore they prefer the bilayer interior according to [24]. Chaotropic anions are large in size and polarizable and are enriched in the vicinity of the oxyethylene groups, whereas kosmotropic anions do not show such a preference and are depleted in the vicinity of the oxyethylene groups [25].

Thus, chaotropic perchlorate ions may approach closely water/surfactant interface, and randomize the structure of the water bound with oxyethylene groups of nonionic surfactant Brij30. Therefore bound water fraction decreases in comparison with reverse micelles modified with a pure water. Kosmotropic acetate ions are mostly wandered in the center of water pools and not 
to the peripheral water. Therefore acetate ions do not hinder hydration of oxyethylene groups and bound water fraction remains unchanged as in the case of pure water.

Data obtained by IR investigations are in good agreement with NMR results. As known, an increase in bound water fraction in the aqueous core leads to the water proton chemical shift more towards higher fields and the observed chemical shift of water proton resonances are the sum of the average chemical shifts of protons in various states of water. Particularly, bound water molecules exhibit proton chemical shift in a relatively upfield direction whereas the chemical shifts of proton resonances of apparently free water appear toward downfield, approaching that of ordinary water [26]. Probably the high content of free water fraction in the presence of potassium perchlorate in comparison with acetate ions, causes the higher values of chemical shift in case of perchlorate ions than in the presence of acetate ions (Fig.3).

\subsection{UV-visible spectroscopic study}

Proposed study is based on the difference in the absorption of electromagnetic radiation between molecules of optical probe bound to micelles and those free in the bulk phase. As an optical probe, o-NA was selected, because it is a small organic molecular probe and causes only infinitesimal perturbance of the reverse micelles. Besides its spectral changes are investigated in detail for characterization of the interface of sodium bis (2-ethylhexyl) sulfosuccinate reverse micelles $[27,28]$.

Absorption spectra of o-NA in hexane/Brij-30 reverse micelles as a function of Brij-30 concentration at $\mathrm{W}_{0}=0$ are given in Fig. 7. It should be mentioned that $\mathrm{W}=0$ corresponds to a system with no addition of water and its presence corresponds to the intrinsic humidity of the system.

For Brij-30 concentration greater than $0.2 \mathrm{M}$ the absorption spectrum remains unchanged (Fig.8). This means that the probe is fully bound to the micelle at the mentioned concentration. Strength of binding of o-NA with Brij-30 micelles were estimated through the binding constant $\left(\mathrm{K}_{\mathrm{b}}\right)$. Binding constants of o-NA with Brij-30 reverse micelles are greater in the presence of perchlorate than acetate (Fig. 9). This result may be explained on the basis of the following considerations: According to IR data (see Figs.5 and 6), water fraction, bound to ethylene oxide groups is less in the presence of perchlorate ions in comparison with additives of acetate ions, hence o-NA binds with polar groups of Brij-30 better and binding constants are higher in the 
presence of additives of perchlorate ions than in case of acetate. In contrast to this, bound water fraction in case of acetate ions is higher than in the presence of perchlorate ions, which presumably hinders binding of o-NA with ethylene oxide groups of Brij-30 and in the results binding constants are lower in the presence of acetate ions than in case of perchlorate.

The proposed explanation may be additionally confirmed by considering the molar concentrations of free and bound fractions of o-NA. As it is shown in Figure 10 the ratio of abovementioned concentrations $\left([\mathrm{o}-\mathrm{NA}]_{\text {free }} /[\mathrm{o}-\mathrm{NA}]_{\text {bound }}\right)$ at the low content of Brij-30 is higher in the presence of acetate ions in the water pools of reverse micelles than in case of perchlorate. This means, that binding of o-NA with ethylene oxide groups of Brij-30 reverse micelles is facilitated in the presence of perchlorate ions in comparison with acetate ions. This may be explained analogously as in section 3.3. viz. chaotropic perchlorate ions may approach closely water/surfactant interface, and randomize the structure of the water bound with ethylene oxide groups of nonionic surfactant Brij-30, thereby o-NA binds with them easily. There is no difference in the ratio of [free]/[bound]) fractions of o-NA at the higher concentration of Brij-30 in the presence of both types of ions.

\section{Conclusions}

The structure of nonionic surfactant Brij-30 reverse micelles under the influence of ionic structure-making and structure-breaking ionic additives was studied.

The chemical shift of water proton magnetic resonance changes to downfield direction with increasing water/surfactant ratio. Herewith, the values of chemical shifts in the presence of chaotropic perchlorate ions are higher than their values in case of kosmotropic acetate additives.

According to infrared spectroscopy data perchlorate ions promote an increasing of free water fraction in the water pockets of the reverse microemulsions, but acetate ions support formation of the bound water.

The sizes of micelles are increased more in the presence of perchlorate ions than in the presence of acetate ions with increasing water/surfactant ratio.

Binding constants of o-NA with Brij-30 reverse micelles are greater in the presence of perchlorate than acetate according to UV-visible spectroscopic study. 
The revealed changes in: a) ratio of the free, bound and trapped water fractions; b) chemical shift of water proton magnetic resonance; c) sizes of water droplets and d) binding constants of molecular probe with reverse micelles under the influence of salts additives may be will introduce some insight in the complex structure of nonionic reversed micelles.

\section{Acknowlegments}

Prof. M.Rukhadze thanks DAAD for possibility to carry out DLS experiments. PhD student T.Butkhuzi thanks thanks Shota Rustaveli National Science Foundation Georgia for a grant (No.DP/1/6-480/12) and P. Pradhan (Department of Chemistry, The City College and The City University of New York) for help in NMR experiments.

\section{References}

[1] R. Najjar, Microemulsions - A Brief Introduction. In: Microemulsions - An Introduction to Properties and Applications. InTech. (2012) 3-30.

[2] P.M. Wiggins, Water in Complex environments such as living systems, Physica A. 314(2002) 485491.

[3] A. Maitra, Ph.K. Patanjali. Reverse Micelle as Membrane Mimetic Agent - A Study of Cholesterol Solubilization in Water-Aerosol OT-Isooctane System. In: Surfactants in Solutions, Springer, 1986, Chapter 2, pp. 581-590.

[4] L. Gebicka and M.Jurgas-Grudzinska, Activity and Stability of catalase in Nonionic Micellar and Reverse Micellar Systems, Z.Naturforsch., 59 (2004) 887-891.

[5] R.K. Mitra, S.S. Sinha, P.K. Verma and S.K. Pal, Modulation of Dynamics and Reactivity of Water in reverse Micelles of Mixed Surfactants, Journal of Physical Chemistry B, 112 (2008) 12946-12953.

[6] D J Kerr, T E Wheldon, J G Russell, H R Maurer, A T Florence, G W Halbert, R I Freshney, S B Kaye, The effect of the non-ionic surfactant Brij 30 on the cytotoxicity of adriamycin in monolayer, spheroid and clonogenic culture systems, Eur.J.Cancer Clin. Oncology, 23(1987) 1315-1322.

[7] S.Gupta, S.K. Sanyal, S.Datta and S.P.Moulik, Preparation of prospective plant oil derived microemulsion vehicles for drug delivery. Indian Journal of Biochemistry and Biophysics, 43 (2006) 254-257.

[8] Qi L. and Ma J. Investigation of the Microenvironment in Nonionic Reverse Micelles Using Methyl Orange and Methylene Blue as Absorption Probes. Journal of colloid and interface science. 1998 , 197 , 
$36-42$.

[9] Jain T. K. , Varshney M. and Maitra A. Structural Studies of Aerosol OT Reverse Micellar Aggregates by FT-IR Spectroscopy. Journal of Physical Chemistry. 1989; 93: 7409-7416.

[10] M. Picquart, D.Valdez, H. Vazquez, Wladimir Urbach and Marcel Waks, Bound and Free Water In Surfactant Micelles And Lipid Vesicles, AIP Conference Proceedings, 759 (2005) 103-110.

[11] C. Kumar and D. Balasubramanian, Structural Features of Water-in-Oil Microemulsions, J.Phys. Chem. 84 (1980) 1895-1899.

[12] J.L. Lemyre and A.M. Ritcey, Characterization of a Reverse Micellar System by ${ }^{1} \mathrm{H}$ NMR, Langmuir, 26 (2010) 6250-6255.

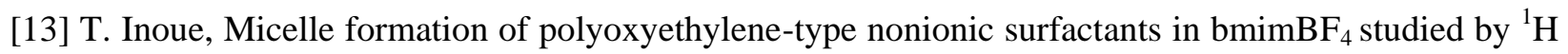
NMR and dynamic light-scattering, Journal of Colloid and Interface Science, 337 (2009) 240-246.

[14] A.M.Durantini, R.D.Falcone, J.J.Silber and N.M. Correa, A New Organized Media: Glycerol: N,NDimethylformamide Mixtures/AOT/n-Heptane Reversed Micelles. The Effect of Confinement on Preferential Solvation, J.Phys. Chem.B 115 (2010) 5894-5902.

[15] Itri R., Caetano W., Barbosa L.R.S., Baptista M.S. Effect of Urea on Bovine Serum Albumin in Aqueous and Reverse Micelle Environments Investigated by Small Angle X-Ray Scattering, Fluorescence and Circular Dichroism. Brazilian Journal of Physics, 2004,Vol.34,No.1,p.58-63.

[16] X. Zhang, Y.Chen, J.Liu, Ch. Zhao and H. Zhang, Investigation on the Structure of Water/AOT/Alcohols Reverse Micelles by Conductivity, Dynamic Light Scattering and Small Angle XRay Scattering, J.Phys. Chem.B 116 (2012) 3723-3734.

[17] T.Butkhuzi, R. Chaladze, N. Lominadze, M. Rukhadze, M. Gvaramia, M.Kurtanidze, G.Bezarashvili, K.Sigua. Study of influence of ionic additives to AOT reverse microemulsions by liquid chromatography, IR and UV-visible spectroscopy. Colloids and Surfaces A: Physicochem. Eng. Aspects, 442 (2014) 98-104.

[18] W.Ch. Chan and H.Y. You, The influence of nonionic surfactant Brij30 on biodegradation of toluene in a biofilter, African Journal of Biotechnology, 9(36) (2010) 5914-5921.

[19] D.E. Koppel, Analysis of macromolecular polydispersity in intensity correlation spectroscopy: the method of cumulants, J.Chem. Phys. 57 (1972) 4814-4820.

[20] B.J.Frisken, Revisiting the Method of Cumulants for the Analysis of Dynamic Light-Scattering Data, Appl. Opt., 40 (2001) 4087-4091.

[21] L.K. Shrestha and K. Aramaki, Structure of Nonionic Surfactant Micelles in Organic Solvents:A SAXS Study. In: Self-organized surfactant structures, edited by Th.F.Tadros, Wiley-VCH, 2012, 17-57.

[22] J. B. Brubach, A. Mermet, A. Filabozzi, P. Calavita, A. Gershel, P. Roy, Infrared investigation of water encapsulated in non ionic reverse micelles , J.Phys. IV France 10 (2000) Pr7-215-218.

[23] J. B. Brubach, A. Mermet, A. Filabozzi, A. Gershel, D. Lairez, M.P. Krafft and P. Roy, Dependence of Water Dynamics upon Confinement Size, J.Phys. Chem. 105 (2001) 430-435. 
[24] J.N.Sachs, Th.B. Woolf, Understanding the Hofmeister Effect in Interactions between Chaotropic Anions and Lipid Bilayers: Molecular Dynamics Simulations. J.Am.Chem.Soc. 125(29)(2003) 87428743.

[25] B. Kronberg, K. Holmberg and B.Lindman, Surface Chemistry of Surfactants and Polymers, First Edition, 2014, John Wiley and Sons. Chapter 7, p.137-152.

[26] A. Maitra, Determination of Size Parameters of Water-Aerosol OT-Oil Reverse Micelles Their Nuclear Magnetic Resonance Data, J. Phys. Chem. 88 (1984) 5122-5125.

[27] N.M. Correa, J.J. Silber, Binding of Nitroanilines to Reverse Micelles of AOT n-Hexane, J. Mol. Liq. 72 (1997) 163-176.

[28] R.D. Falcone, J.J. Silber, M.A. Biasutti, N.M. Correa, Binding of o-Nitroaniline to Nonaqueous AOT Reverse Micelles, Organic Chemistry in Argentina, ARKIVOC, vii, (2011) 369-379.

\section{Captions}

Figure 1. 1H NMR spectrum of 0.5M Brij-30 in hexane in the absence (a) and presence (b) of water $\mathrm{W}=1$.

Figure 2. Dependence of proton chemical shift on water/Brij-30 molar ratio.

Figure 3. Diagram of variation of chemical shift of water proton magnetic resonance in water-inoil micellar solutions in the presence of $0.05 \mathrm{M}$ sodium acetate ( $\mathbf{n})$ and $0.05 \mathrm{M}$ potassium perchlorate $(\square)$ at various $\mathrm{W}_{0}$. Concentration of Brij-30 corresponds to $0.50,0.33$ and $0.25 \mathrm{M}$ at $\mathrm{W}=1.0,1.5$ and 2.0 respectively.

Figure 4. Deconvoluted infrared spectrum for water/Brij-30/hexane system $\mathrm{W}_{0}=1$. Curves with lines ---- correspond to trapped water, with lines ----•-- correspond to bound water and - - curves represent free bulk water. The dots correspond to experimental data. The solid lines correspond to the sum of the deconvoluted spectrum of the water, i.e. sum of surfaces of trapped, bound and free water peaks. $\mathrm{SD}=0.49$

Figure 5. Deconvoluted infrared spectrum for $0.05 \mathrm{M}$ sodium acetate/Brij-30/hexane system $\mathrm{W}_{0}=1$. Curves with lines ---- correspond to trapped water, with lines --.--·- correspond to bound water and - - - curves represent free bulk water. The dots correspond to experimental data. The solid lines correspond to the sum of the deconvoluted spectrum of the water, i.e. sum of surfaces of trapped, bound and free water peaks. $\mathrm{SD}=1.994$

Figure 6. Deconvoluted infrared spectrum for $0.05 \mathrm{M}$ potassium perchlorate/Brij-30/hexane system $\mathrm{W}_{0}=1$. Curves with lines ---- correspond to trapped water, with lines --.--- correspond to bound water and - - - curves represent free bulk water. The dots correspond to experimental 
data. The solid lines correspond to the sum of the deconvoluted spectrum of the water, i.e. sum of surfaces of trapped, bound and free water peaks. $\mathrm{SD}=1.789$

Figure 7. Absorption spectra of o-NA in hexane ( $)$ ) $0.0 \mathrm{M}$ Brij-30, (匹) $0.13 \times 10^{-2} \mathrm{M}$ Brij-30;

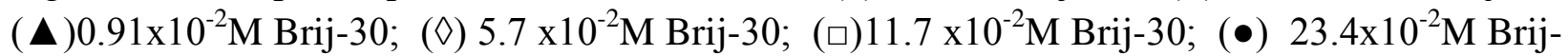

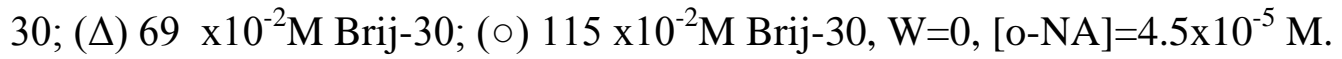

Figure 8. Variation of $\lambda_{\max }$ of o-NA in reverse micelles as a function of Brij-30 concentration.

Figure 9. Diagram of binding constants of o-NA with Brij-30 micelles in the presence of $0.05 \mathrm{M}$ sodium acetate $(\boldsymbol{\square})$ and $0.05 \mathrm{M}$ potassium perchlorate $(\square)$.

Figure 10. Dependence of ratio of free to bound fraction of o-NA on the concentration of Brij-30 in the reverse microemulsions in the presence of acetate $(\Delta)$ and perchlorate $(\bullet)$ ions. 
Table 1. Sizes of Brij-30 reverse micelles determined by DLS

\begin{tabular}{|c|c|c|c|c|c|}
\hline $\begin{array}{l}\text { Concentration of } \\
\text { Brij-30, M }\end{array}$ & $\begin{array}{l}\text { Water/surfactant } \\
\text { ration, W }\end{array}$ & Additive type & Size, $\mathrm{nm}$ & Additive type & Size, $\mathrm{nm}$ \\
\hline \multirow{3}{*}{0.5} & \multirow{3}{*}{1} & Pure water & 2.99 & Pure water & 2.99 \\
\hline & & $\begin{array}{l}0.05 \text { M Sodium } \\
\text { acetate }\end{array}$ & 3.06 & $\begin{array}{l}0.1 \mathrm{M} \text { Sodium } \\
\text { acetate }\end{array}$ & 2.98 \\
\hline & & $\begin{array}{l}0.05 \text { M Potassium } \\
\text { perchlorate }\end{array}$ & 2.99 & $\begin{array}{l}\text { 0.1 M Potassium } \\
\text { perchlorate }\end{array}$ & 2.94 \\
\hline \multirow{3}{*}{0.5} & \multirow{3}{*}{2} & Pure water & 3.34 & Pure water & 3.34 \\
\hline & & $\begin{array}{l}0.05 \text { M Sodium } \\
\text { acetate }\end{array}$ & 3.33 & $\begin{array}{l}0.1 \mathrm{M} \text { Sodium } \\
\text { acetate }\end{array}$ & 3.42 \\
\hline & & $\begin{array}{l}0.05 \text { M Potassium } \\
\text { perchlorate }\end{array}$ & 3.30 & $\begin{array}{l}0.1 \text { M Potassium } \\
\text { perchlorate }\end{array}$ & 3.40 \\
\hline \multirow{3}{*}{0.5} & \multirow{3}{*}{4} & Pure water & 3.93 & Pure water & 3.93 \\
\hline & & $\begin{array}{l}0.05 \mathrm{M} \text { Sodium } \\
\text { acetate }\end{array}$ & 3.90 & $\begin{array}{l}0.1 \mathrm{M} \text { Sodium } \\
\text { acetate }\end{array}$ & 3.93 \\
\hline & & $\begin{array}{l}0.05 \text { M Potassium } \\
\text { perchlorate }\end{array}$ & 4.08 & $\begin{array}{l}\text { 0.1 M Potassium } \\
\text { perchlorate }\end{array}$ & 4.09 \\
\hline \multirow{3}{*}{0.5} & \multirow{3}{*}{8} & Pure water & 6.77 & Pure water & 6.77 \\
\hline & & $\begin{array}{l}0.05 \mathrm{M} \text { Sodium } \\
\text { acetate }\end{array}$ & 6.59 & $\begin{array}{l}0.1 \text { M Sodium } \\
\text { acetate }\end{array}$ & 6.61 \\
\hline & & $\begin{array}{l}0.05 \text { M Potassium } \\
\text { perchlorate }\end{array}$ & 6.74 & $\begin{array}{l}\text { 0.1 M Potassium } \\
\text { perchlorate }\end{array}$ & 7.36 \\
\hline
\end{tabular}


Table 2. Ratio of free, bound and trapped water fractions in the water pockets of Brij-30 reverse micelles

\begin{tabular}{|l|c|c|c|c|}
\hline Additive & \multirow{2}{*}{ W } & \multicolumn{3}{|c|}{ Water,\% } \\
\cline { 3 - 5 } & 1 & Free & Bound & Trapped \\
\hline Water & 1 & 46 & 47 & 7 \\
\hline $\begin{array}{l}\text { Sodium } \\
\text { acetate }\end{array}$ & 1 & 68 & 46 & 13 \\
\hline $\begin{array}{l}\text { Potassium } \\
\text { perchlorate }\end{array}$ & & & 25 & 7 \\
\hline
\end{tabular}




\section{$\frac{\mathrm{CH}_{3}\left(\mathrm{CH}_{2}\right)}{\mathrm{D}}{ }_{10} \frac{\mathrm{CH}_{2}}{\mathrm{~A}}-\frac{\mathrm{O}}{-\mathrm{CH}_{2}-\mathrm{CH}_{2}}-\frac{\mathrm{O}}{\mathrm{C}}-\frac{\mathrm{CH}_{2}-\mathrm{CH}_{2}}{\mathrm{C}}-\frac{\mathrm{O}}{\mathrm{CH}_{2}-\mathrm{CH}_{2}}-\frac{\mathrm{O}}{\mathrm{C}}-\frac{\mathrm{CH}_{2}-\mathrm{CH}_{2}}{\mathrm{~B}}-\mathrm{OH}$}
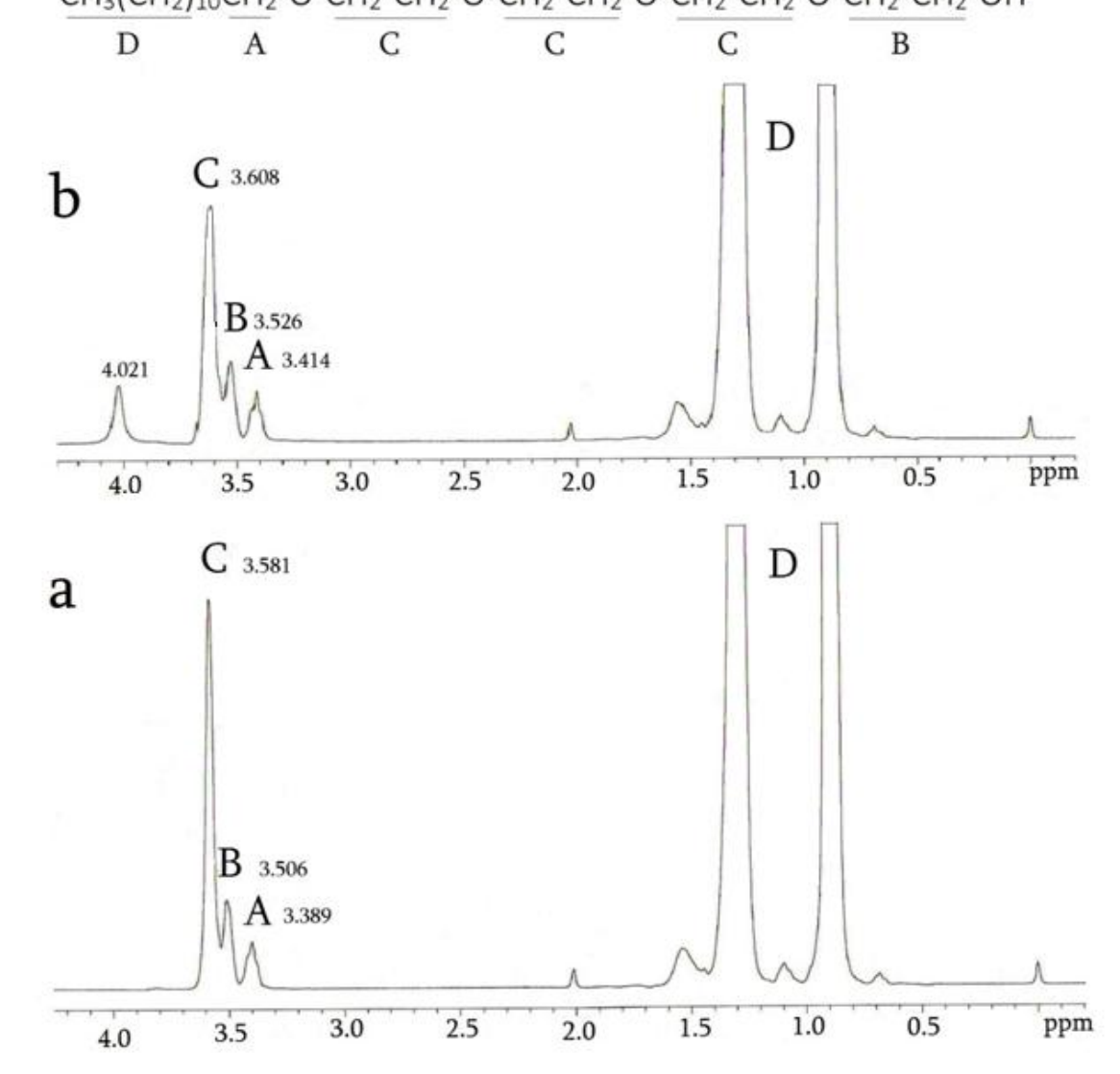

Figure 1. 


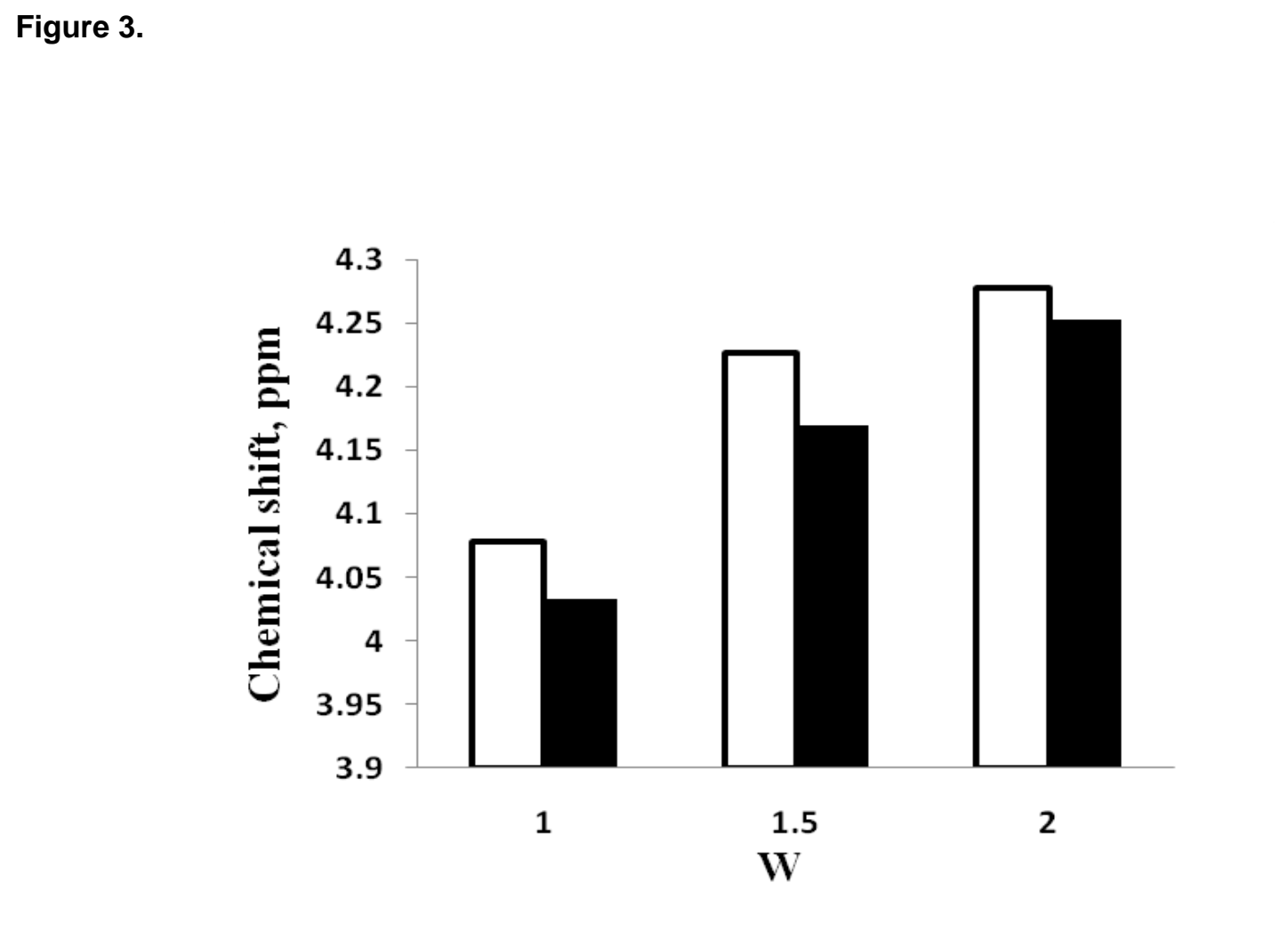

Figure 3.

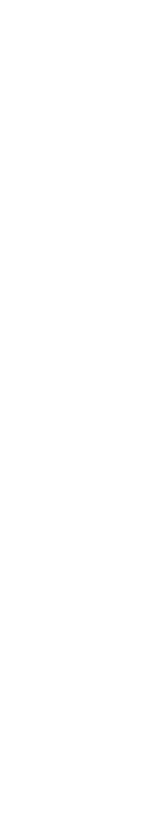

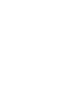

.

.
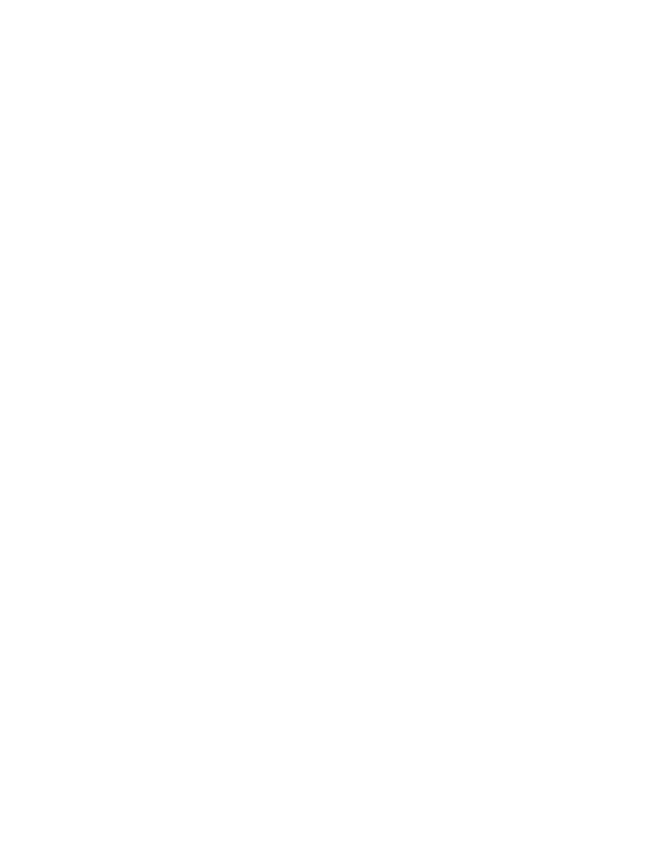
Figure 4.

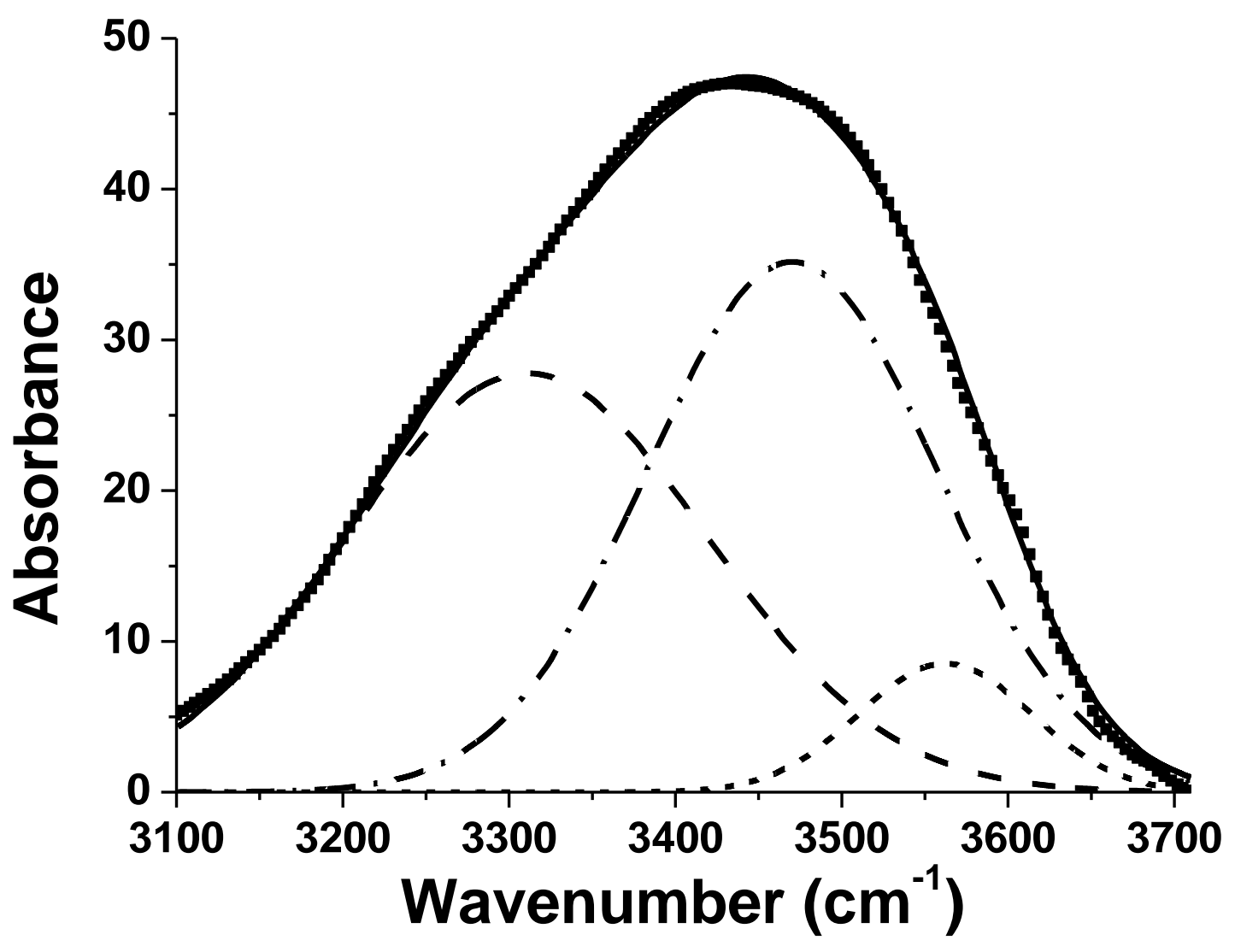




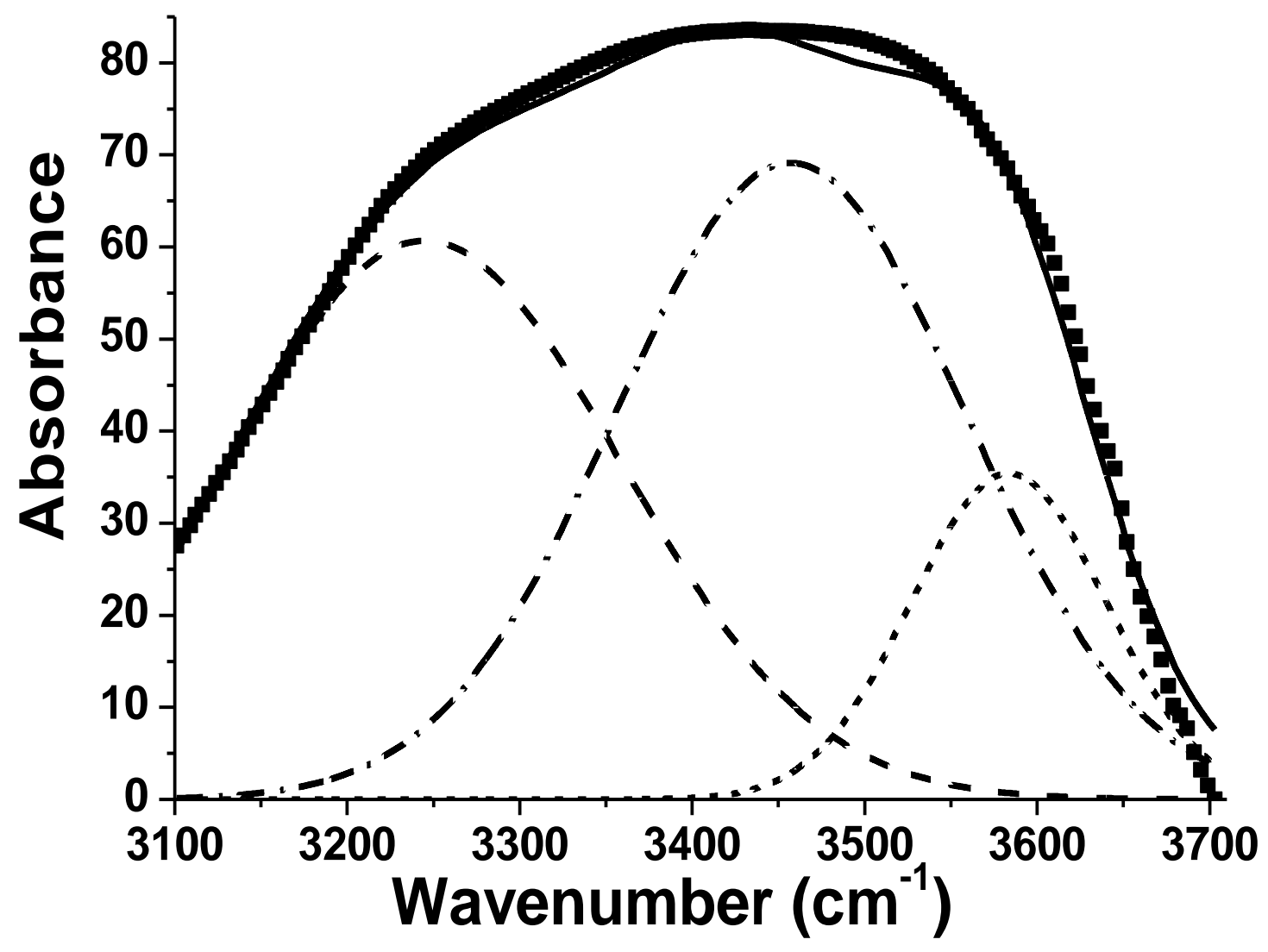

Figure 5. 


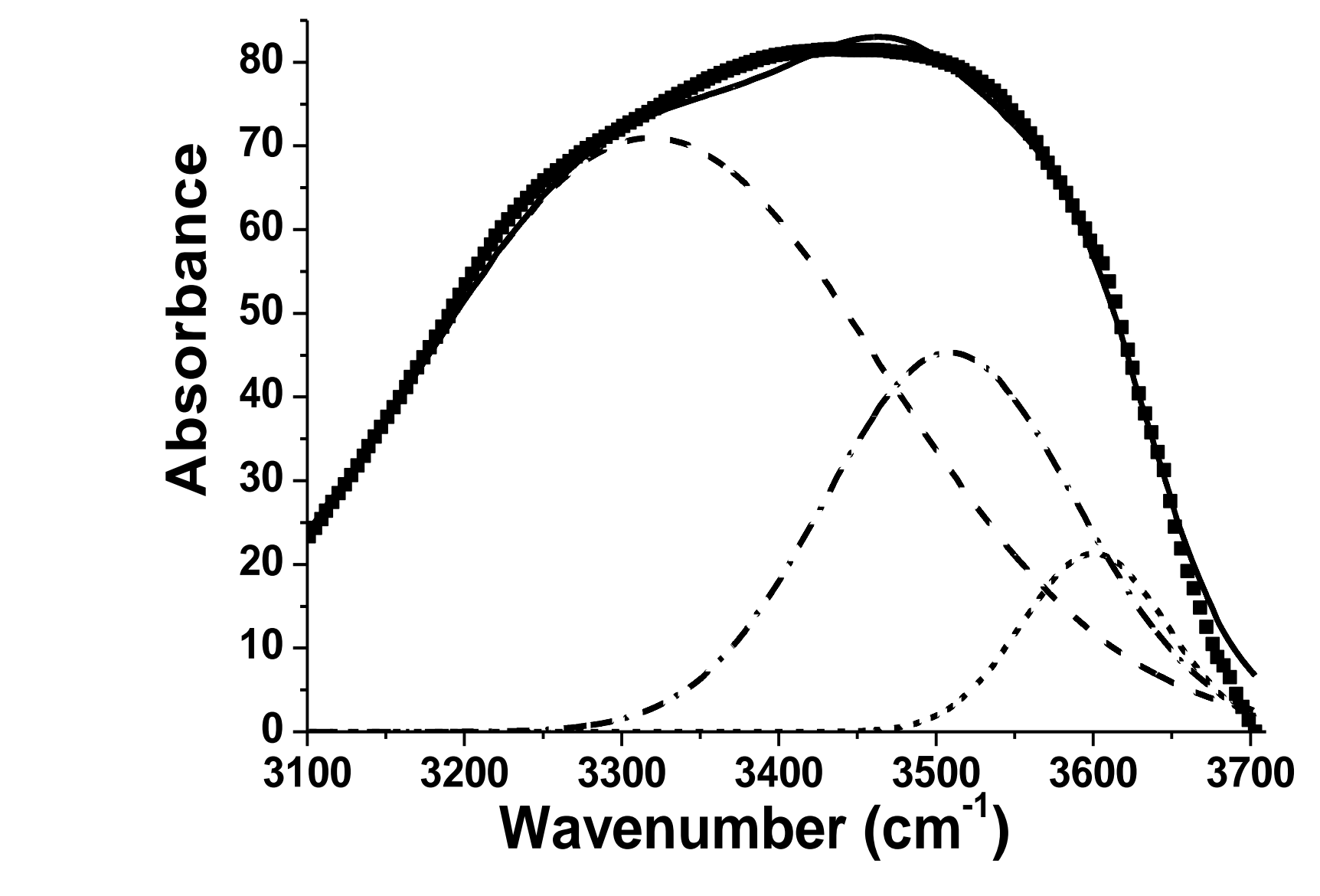

Figure 6.

(⿸丆口

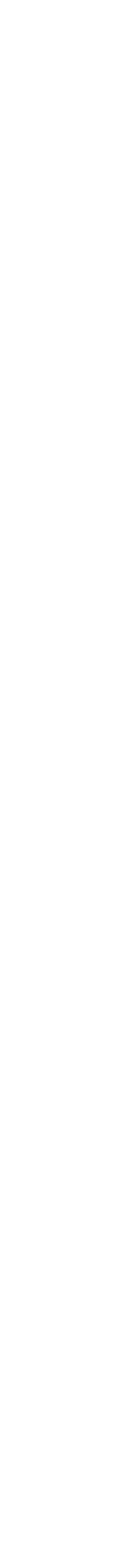

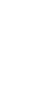


Figure 7.

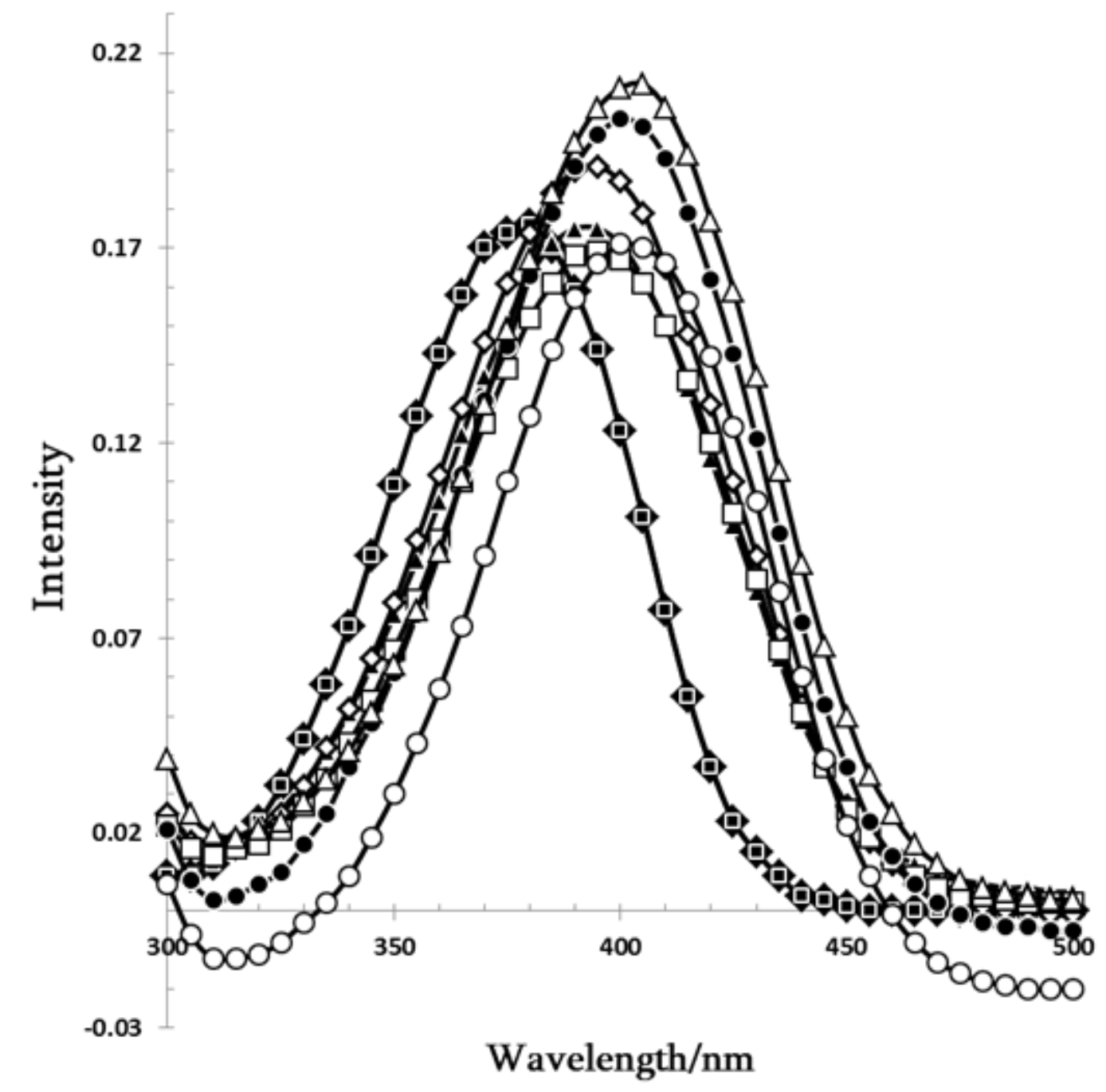




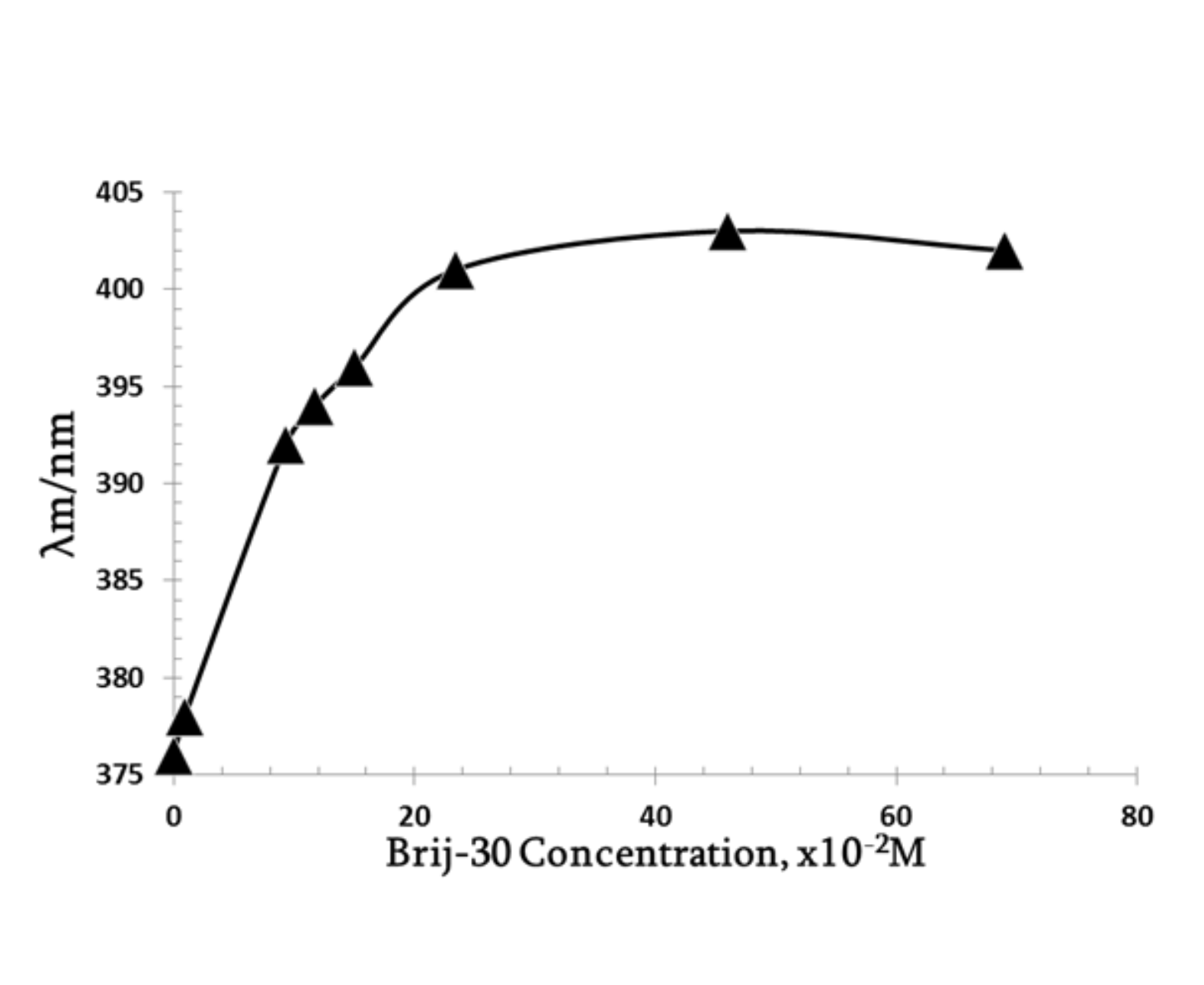

Figure 8

Figure 8.

80

(

Figure 8

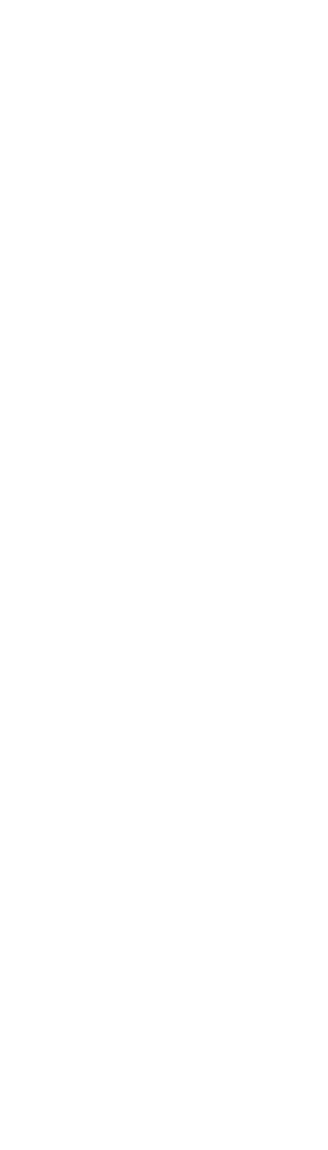

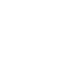

.

.
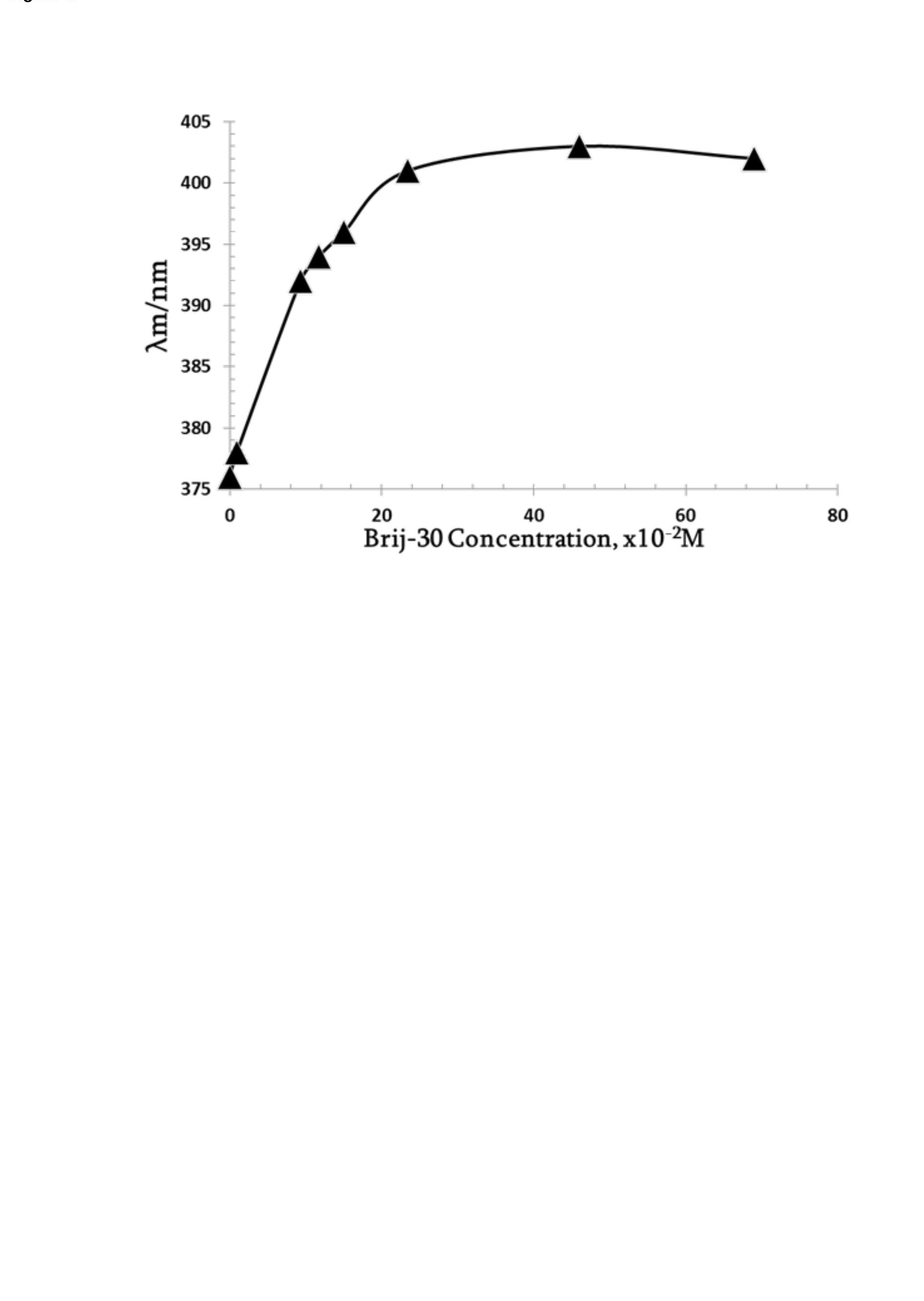


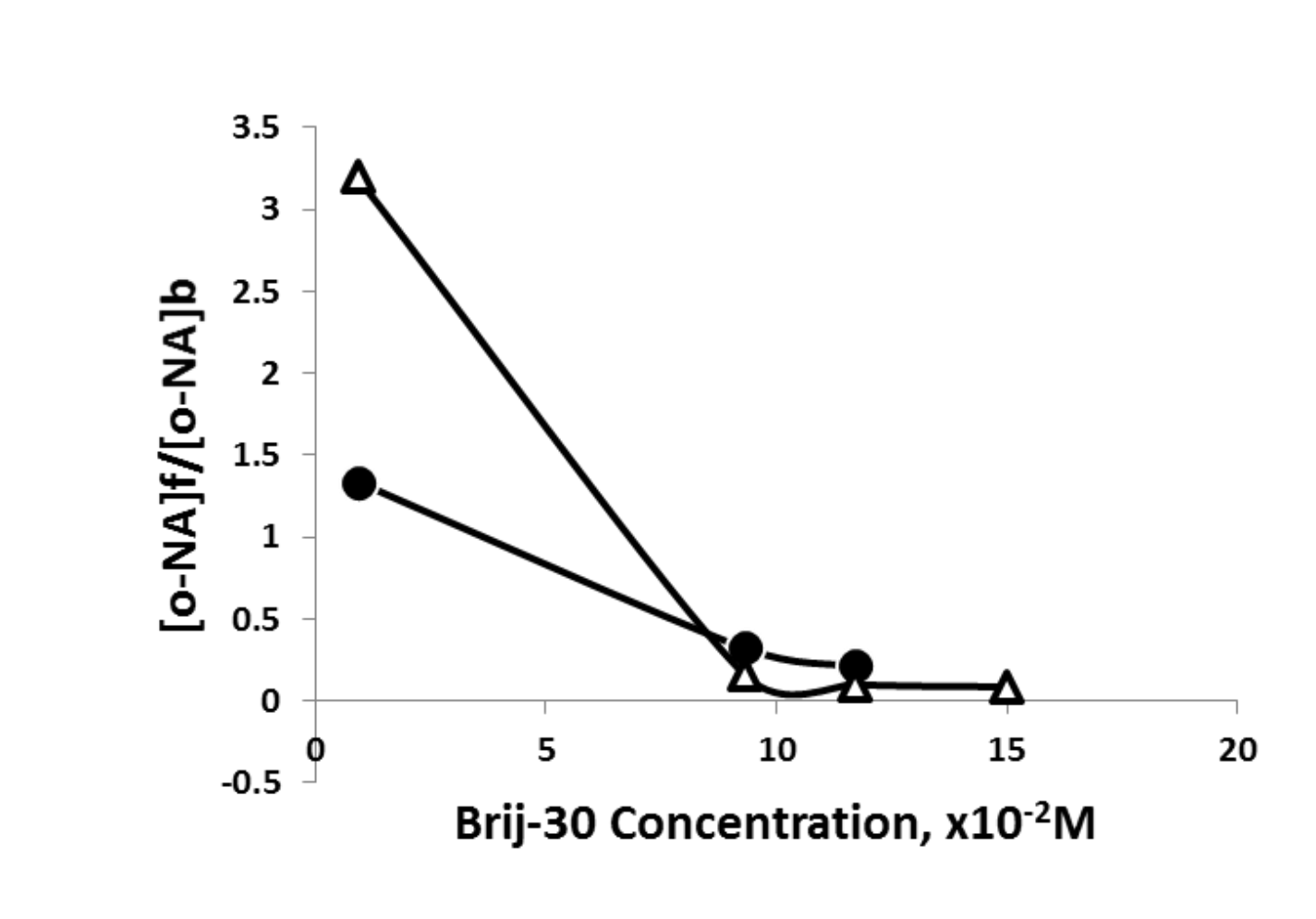
Figure10 0

.
a

.
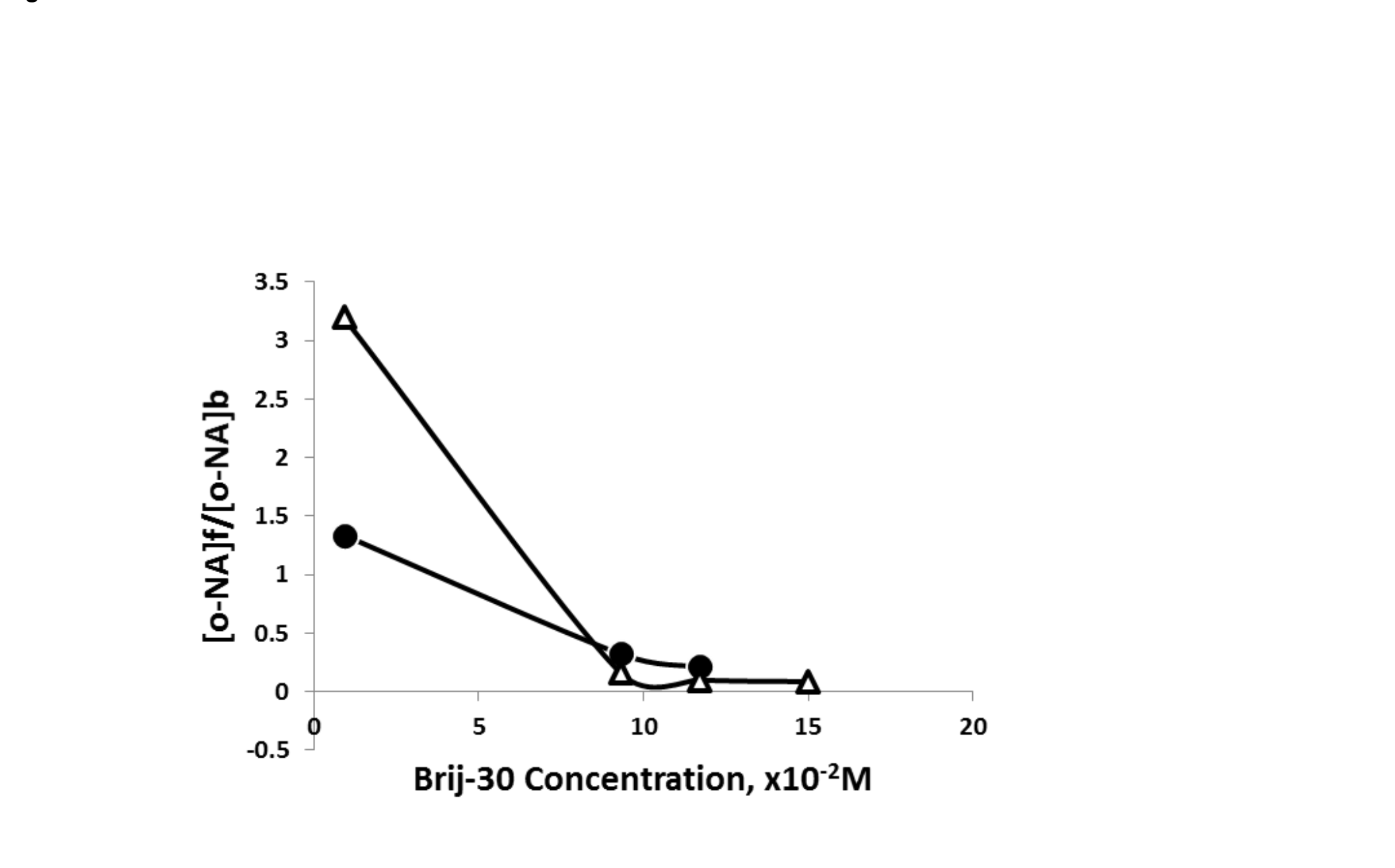
.

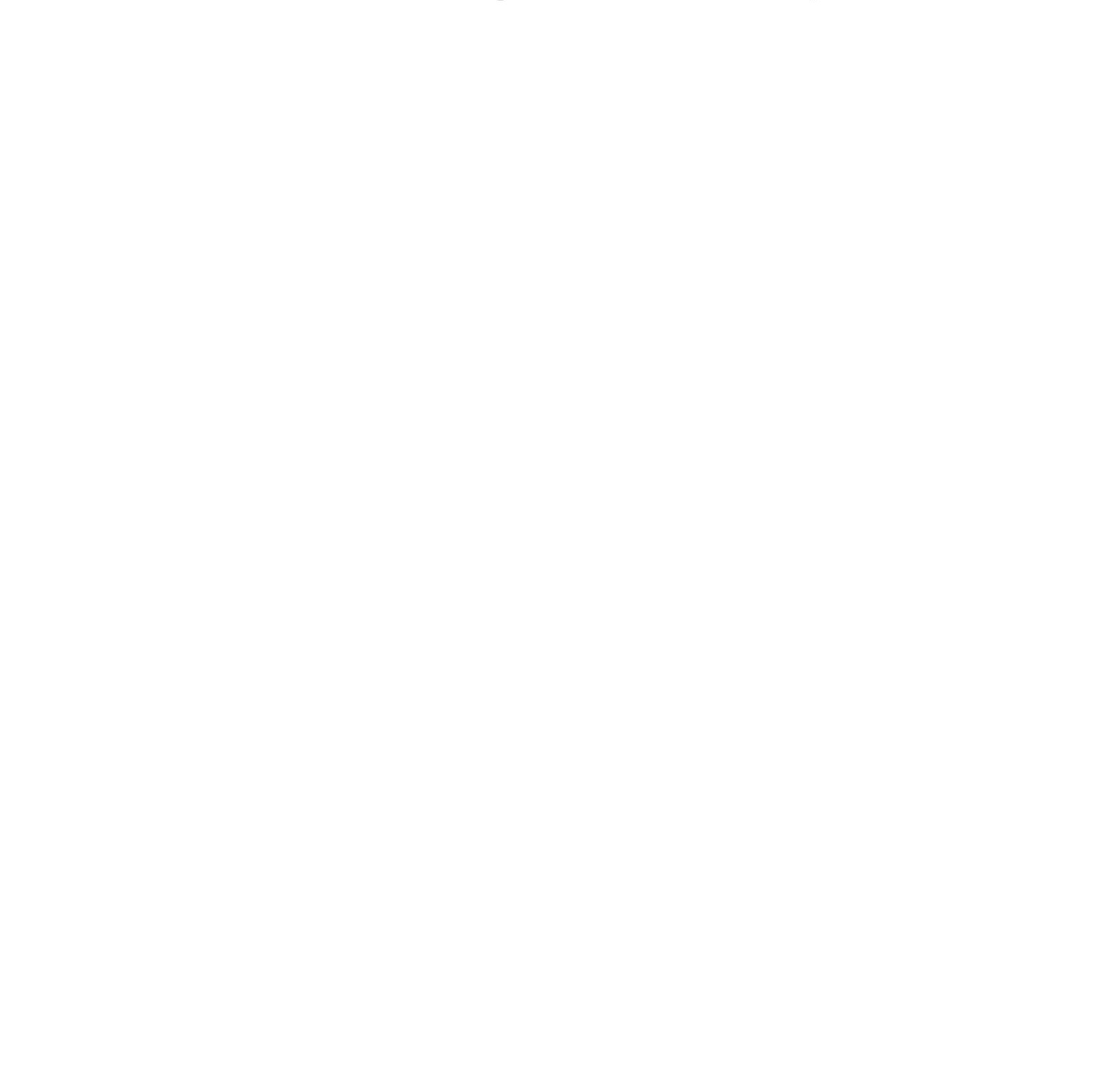




\begin{abstract}
The microenvironment of water droplets of nonionic polyoxyethylene (4) lauryl ether reverse micelles was investigated using infrared, ultraviolet-visible and nuclear magnetic resonance spectroscopy, also by dynamic light scattering. The different influence of kosmotropic and chaotropic ionic additives on the microstructure of reverse micelles was revealed. The values of chemical shift in the presence of structure-breaking perchlorate ions are higher than their values in case of structure-making acetate ions according to measurements by proton magnetic resonance spectroscopy. Deconvolution of the $\mathrm{O}-\mathrm{H}$ stretching vibrational absorption spectra in the region of $3000-3800 \mathrm{~cm}^{-1}$ into three subpeaks with a Monte Carlo method showed that perchlorate ions promote an increasing of free water fraction in the water pools of the reverse micelles, whereas acetate ions support formation of bound water. Influence of salt additives results in slight different sizes of water droplets, measured by dynamic light scattering method. Different influence of kosmotropic and chaotropic anions on binding constant $\mathrm{K}_{\mathrm{b}}$ of optical probe to oxyethylene groups was revealed.
\end{abstract}




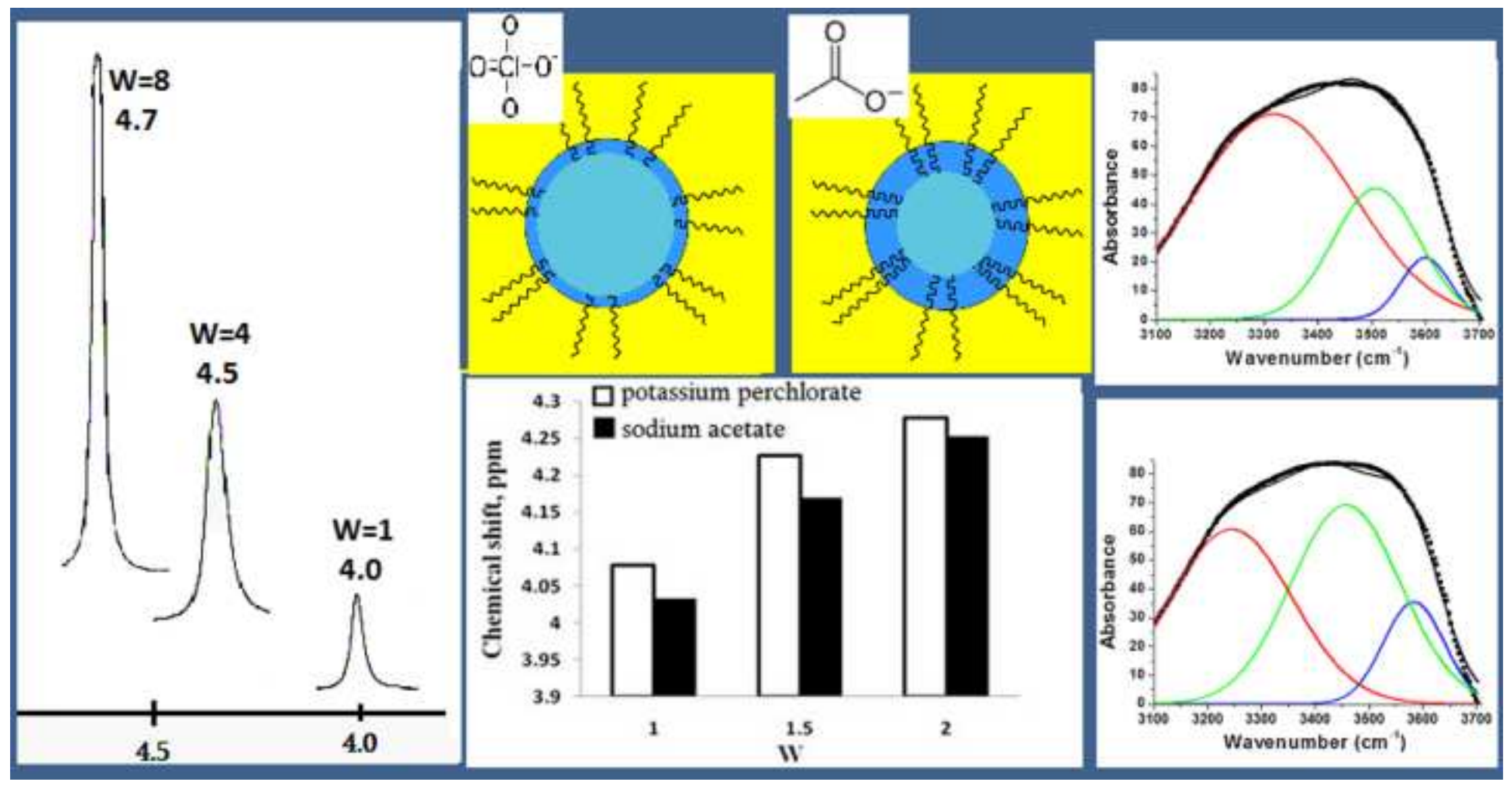

